\title{
Age, previous conviction, and psychopathic disorder were associated with conviction after discharge from high security hospitals
}

\author{
Buchanan A. Criminal conviction after discharge from special (high security) hospital. Br J Psychiatry 1998 Jun;172:472-6.
}

\section{Questions}

In patients leaving special, high security hospitals, what is the frequency and type of subsequent criminal conviction and are there any risk factors for subsequent conviction?

\section{Design}

Inception cohort followed up for 10.5 years.

\section{Setting}

England and Wales.

\section{Patients}

425 patients (mean age 38 y, 82\% men) who were discharged from special, high security hospitals in England and Wales in 1982 and 1983. $281(66 \%)$ were discharged to hospitals with lesser degrees of security, $122(29 \%)$ went home or to a hostel, and $22(5 \%)$ went back to prison. 190 patients $(45 \%)$ had been classified as suffering from a mental illness, 141 (33\%) from a psychopathic disorder, $72(17 \%)$ as mentally impaired, and 45 $(11 \%)$ as severely mentally impaired $(6 \%$ had a dual classification).

\section{Assessment of prognostic factors}

Data pertaining to sex, age at discharge, number of criminal convictions before entering the special hospital, grounds for detection under the Mental Health Acts of 1959 and 1983, and location immediately after discharge were obtained from hospital records.

\section{Main outcome measures}

Type and frequency of criminal conviction obtained from the Offenders Index through the Research Statistics Department of the Home Office.

\begin{abstract}
Main results
5.5 years after hospital discharge a criminal conviction had been recorded in $24 \%$ of the cohort; $9 \%$ had been convicted of a serious offence, $8 \%$ of a violent offence, and $5 \%$ of a sexual offence. 10.5 years after hospital discharge 133 patients (31\%) had convictions of any offence, $14 \%$ of a serious offence, $14 \%$ of a violent offence, and $7 \%$ of a sexual offence. After controlling for other variables, results of logistic regression showed that age at discharge (odds ratio [OR] $0.96 \quad\{95 \% \text { CI } 0.95 \text { to } 0.98\}^{*}$ $\mathrm{p}=0.002$ ), previous conviction (OR 1.09 \{CI 1.06 to 1.11$\}^{*}$ $\mathrm{p}<0.001$ ), and a legal classification of psychopathic disorder (OR $1.68\{\text { CI } 1.33 \text { to } 2.13\}^{*} \mathrm{p}=0.03$ ) were associated with conviction after hospital discharge. Thus, being a younger age at discharge, having a previous conviction, and being assigned to the legal category of psychopathic disorder increased the odds of conviction after hospital discharge.
\end{abstract}

\section{Conclusion}

Age at discharge, previous conviction, and a legal classification of psychopathic disorder were associated with conviction after discharge from special, high security hospitals.

*Numbers calculated from data in article.

Source of funding: Special Hospitals Service Authority.

For correspondence: $\mathrm{Dr}$ A Buchanan, Department of Forensic Psychiatry, Institute of Psychiatry, De Crespigny Park, London SE5 8AF, UK. Fax +44 (0)171 2770283.

\section{Commentary}

The prediction of recidivism among mentally disordered offenders is an important and difficult task. The accuracy of clinical predictions has often been questioned, but recent research has the potential of greatly improving risk assessments. Risk assessments are likely to be accurate to the extent that they consider factors related to recidivism. Unfortunately, many of the standard factors considered by mental health professionals, such as subjective distress and psychiatric symptoms, have not been found to predict recidivism. ${ }^{1}$ The findings by Buchanan that age, psychopathy, and previous criminal history predict future criminal behaviour among mentally disordered offenders is consistent with a long line of research on general offenders. ${ }^{2}$ More than 282 studies have examined the association between previous criminal history and recidivism among adult offenders (average $r=0.16){ }^{2}$ We now know that the same factors that predict recidivism among general criminal offenders also predict criminal recidivism among mentally disordered offenders. ${ }^{1}$

The predictive accuracy of any single factor, however, is limited. The prudent clinician should consider a range of empirically validated risk factors. The most accurate risk assessments use structured scales, which not only specify the factors to consider but also how the factors should be combined. Two of the more promising structured risk assess- ment instruments are the Level of Service Inventory-Revised and the Violence Risk Appraisal Guide. ${ }^{34}$

R Karl Hanson, PhD Department of the Solicitor General of Canada

Ottawa, Ontario, Canada

1 Bonta J, Law M, Hanson K. The prediction of criminal and violent recidivism among mentally disordered offenders: a meta-analysis. Psychol Bull 1998;123:123-42.

2 Gendreau P, Little T, Goggin C. A metaanalysis of the predictors of adult offender analysis of the predictors of adult offender
recidivism: what works! Criminology 1996;34: 575-607.

3 Andrews DA, Bonta J. The level of service inventory-revised. Toronto: Multi-Health Systems, 1995.

4 Harris GT, Rice ME, Quinsey VL. Violent recidivism of mentally disordered offenders: the development of a statistical prediction instrument. Criminal Justice and Behavior 1993; 20:315-55 